\title{
LLORET DE MAR: \\ DESTRUCCIONS I RESISTENCIES D'UN POBLE EN MANS DEL TURISME
}

\author{
Jordi Estivill \\ (Universitat de Perpinyà)
}

En este artículo se tefteja el estado actual de una investigación socioantropológica en curso, sobre las transformaciones de un pueblo de la Costa Brava sometido a las presiones de signo diverso, de una enorme ola turística (más de 100.000 personas en el mes de agosto), de la inmigración del sur de España y de la burguesía autóctona. ¿Hasta qué punto el tejido social del pueblo se resquebraja y se rompe con la destrucción de la economía tradicional -el paso de una actividad extractiva al dominio del terciario- y la renovación de más de la mitad de la población estable? ¿Una ruptura de las estructuras productivas engendra un cambio total de las relaciones sociales e ideológicas? La respuesta no es sencilla.

La sociedad de Lloret se ha erosionado debido a: 1) Una mayor dependencia con respecto a un exterior no controlable (financiero, tours operators, mano de obra, producción para el consumo, etc.) 2) Una alteración de los centros y de las formas de poder. 3) Una metamorfosis de Ios ritmos y las manifestaciones de la vida natural y social. 4) Una pérdida de funcionalidad de instituciones y grupos otrora importantes como la familia, la iglesia, la vejez. 5) Un divorcio cada vez mayor entre la cotidianidad y los valores tradicionales. La estructura de las clases sociales también se ha modificado.

Pero, frente a estas mutaciones el edificio social ha encontrado unas acomodaciones económicas e ideológicas, ha reforzado sus lazos internos, se ha hecho más complejo. Por fin, ha resistido tratando de apoyarse en sus cimientos más profundos. 
«Papets»: Revista de Sociología

El resurgimiento actual de las manifestaciones populares catalanas en Llotet, son en cierto modo una salida y una oposición a las tendencias externas de dispersión y de disgregación. Esta reacción se sostiene en unas raíces históricas no desmanteladas, en la diferenciación lingüística, en una trama de prácticas sociales específicas, en una difusa conciencia de pertenencia a una comunidad nacional perseguida. ¿Podría resumirse la cuestión en estos términos: frente al imperialismo, resistencia nacional popular? Demasiado simple para tesponder a la complejidad de la realidad del Lloret 1978. 
«El turismo ha de sustituirse por el viaje sacro y castrense. La Falange probibirá terminantemente, bajo penas severísimas, el turismo. El español hará viajes, resuelto a conquistar en epopeya. Viaje sacro, rezando en Flandes, te. zando en Italia, rezando en Alemania. Viaje castrense, luchando en Francia: el Mediodía contra el Norte.»

García Serrano, revista Arriba España, de Pamplona, 24 septiembre 1936.

Malgrat les curioses i repressores intencions eclesiàstico-militars de la Falange Navartesa de l'any 1936, el fenomen del turisme no ha respectat el santuari espanyol i ha invadit la pell de brau, condicionant no solav ment la seva evolució econòmica sinó també sotragant gran part de les relacions socials i culturals.

\section{Una realitat poc estudiada ${ }^{1}$}

Juntament amb el turisme interior, els més de dos-cents milions de turistes anyals en tot el món, constitueixen una realitat social d'una im. portància inusitada i creixent. El fet de la seva limitació tant en l'espai

1. Uns primers resultats d'aquest estudi sỏcio-antropològic de Lloret de Mar en els quals es comparava l'evolució d'aquesta població amb Sant Cebrià en la Costa Vermella de l'altre costat de la frontera, han vist ja la Ilum pública a la Univetsitat de Perpinyà: «Saint Cyprien et Llotet de Mat: tourisme planifié et tourisme sauvage». Sobre la mateixa qüestió va ésser presentada una ponència I'any 1976 que fou publicada en el volum «Debat Costa Brava». Girona: Cambra de Comerç, 1978. 
(la majoria d'aquests moviments de població tenen lioc a Europa i particularment els acullen les societats mediterrànies), com en el temps (en general a l'estiu) donen a aquesta problemàtica unes característiques específiques i poc estudiades.

La relativa escassetat bibliogràfica, en part s'explica pel caràcter recent de la massificació turística (pràcticament després de la Segona Guerra Mundial), per l'absència de conflictualitat manifesta i per la seva localització en àrees on I'estudi sociològic és més aviat precari (Antilles, Mediterrani, Mèxic, Nord d'Africa).

Tanmateix i malgrat una certa continuitat bibliogràfica posada de manifest per Lancaster i Nichols, ${ }^{2}$ és en els anys seixanta i setanta que creix l'interès dels estudiosos pel fenomen turístic.

En Ilurs publicacions els economistes discuteixen els efectes positius $^{3} \mathrm{i} / \mathrm{o}$ negatius ${ }^{4}$ del turisme sobre el consum, les rendes, l'ocupació $\mathrm{i}$ els equipaments collectius. S'interessen per la influència d'aquest fenomen sobre el desenvolupament d'una zona ${ }^{5}$ o d'un país. ${ }^{6}$ Els geògrafs posen de telleu els factors locacionals, les transformacions territorials i els moviments migratoris. ${ }^{7}$ Amb freqüència els sociòlegs i antropòlegs situaven l'activitat turística en el marc de les anàlisis sobre el consum i l'oci. ${ }^{8} \mathrm{I}$ molt sovint, la majoria d'aquests plantejaments es deixaven anar pel pendent del voluntarisme més metafísic presentant el turisme com la nova forma d'evitar les guerres i com el camí ideal vers un món harmònic.

Contrastant amb les darteres afrmacions, a començaments dels anys setanta apareixen noves aproximacions de caire més crític. Així per exemple, en el Congrés anual de l'Associació Americana d'Antropòlegs celebrat a Mèxic l'any 1974 es presenten un conjunt de ponències que posen les

2. Lancaster, J., Nichols, L., «A selected bibliography of geographical references and related research in ontdeor recreation and tourism 1930-1971». Exchange Bibliography núm. 190. Illinois: Council of Planing Librarians.

3. Kaspar, C., «Le phénomène multiplicateur du tourisme», La Gazette Officielle du Tourisme, núm. 113. París, 1966.

4. Rosemberg, H., i Reiter, R., «Rural workers in french Alpine tourism: whose development», Studies in Europedn Society, núm. 1, 1973.

5. Faure, A., «Le rôle ău tourisme dans la stratégie du développement», VII Colloque FrancoEspagnol des Facultées de Droit Pyrénéennes, Montpeller, 1968.

6. Baretje, R., Aspects économiques du tourisme (París: Berger-Levrault, 1972). stends.

7. Withington, W. A, Upland resorts and tourism in Indonesia. Some recent

8. Dumazedier, J., Vers une civilisation du loisir (París: Du Seuid, 1966). 
fites d'una interpretació més a prop de la realitat "i a la qual hom incorpora la dimensió política. Nash fins i tot identifica el turisme com una de les plasmacions de l'imperialisme. ${ }^{10}$ Ara bé, la disparitat entre la importància creixent d'aquest moviment de població estable i l'atenció crítica dels estudiosos de ciències socials continua. Pràcticament són gairebé inexistents les recerques sobre el turisme com a fenomen global, que el situïn en les relacions entre les metròpolis i les colònies, entre els països industrialitzats i els endarterits. Que insisteixin en el paper de la perifèria subdesenvolupa$\mathrm{da}$, proveïdora de mà d'obra, de productes agrícoles i d'esbarjo. Que posin l'accent en el turisme com a nova font d'acumulació de la fase actual de desenvolupament del capitalisme. Que expliquin la monopolització $\mathrm{i}$ la intexnacionalització creixent dels canals de turistificació (hotels, agències, urba. nitzacions, tour operator, etc.). Que l'emmarquin en la degradació de les condicions de vida de les societats altament urbanitzades $i$ industrialitzades, i en la necessitat d'alliberat-se'n tot i que sigui adoptant comportaments encara més alienats.

Adhuc escassejen més els estudis del turisme lligats amb les classes socials dels països "productors de turisme» $\mathrm{i}$ amb les dels que l'acullen, $\mathrm{i}$ dels processos d'interinfluència entre uns $i$ altres. Com les societats recep. tores passen d'una economia extractiva a una de serveis? De quina forma es transformen les classes socials? Quines noves pautes de comportament apareixen, quins valors morals desapareixen? Com es modifica la cultura autòctona? Preguntes i més preguntes que per ara queden en l'aire.

\section{«Spain is different»}

No obstant que aquest lema hagi estat utilitzat per a vendre la «pa. radisiaca península», no sembla que defineixi l'especificitat de la producció intellectual autòctona sobre el turisme ja que ha seguit un procés semblant al que s'ha descrit esquemàticament per les publicacions estrangeres. També hom pot trobar aquí elogis al paper antibellicós i d'apropament entre els pobles i càlculs tècnics sobre el millorament del nivell de vida deguts al turisme. Un exemple d'aquests darrers, els trobem en les obres d'Arrillaga, ${ }^{\text {II }}$

9. Deitch, L., The impact of Tourism upon the Arts and Crafts of the Indians of the South Western United States (Mexic: 1974). Fraser T., The impact of tourism in the Windmerd Islands (Mèxic, 1974).

10. Nash, D., Tourism as a form of imperialism (Mexic, 1974).

11. Arrillaga, J. I., El turismo en la economia nacional (Madrid: Nacional, 1955). Sistema de politica turistica (Madrid: Aguilar, 1955). Ensayos sobre turismo (BarceIona: Editur, 1962). 
i de Pulido. ${ }^{12}$ Un exemple de la retòrica metafísica es manifesta en el paràgraf següent: «Tan lejos como el más remoto país desde el que, con la paz en el alma, con la paz como objetivo, con la paz, llega el turista [...]. Esta es una realidad indiscutible: el turismo es Paz, es Progreso, es Prosperidad y Cultura $y$ Ecumenismo.» ${ }^{13}$

Contrastant pel seu rigor amb aquestes afirmacions gratuites, cal notar els estudis de Barceló i Pons. ${ }^{14}$ L'any 1964 estudiava la històtia del turisme a les Illes Balears i avançava unes primeres tipologies cronològiques. No és d'estranyat que sigui a mallorquins a qui devem unes primícies d'anàlisi sobre els inicis històrics i l'espectacularitat de les manifestacions turístiques localitzades a Mallorca. La transformació de l'economia illenca en el sentit d'un monocultiu turístic ha preocupat a tots els que s'inquieten pel seu futurs. Els estudis d'A. Tarabini, J. Roca, A. Rabassa, J. Bastard, ${ }^{15}$ s'inscriuen en aquesta línia. Aixi com també ho fan els capítols, dedicats al mencionat sector, de les recents investigacions referides a la situació econòmica de Mallorca i Menorca. ${ }^{16}$ Sociòlegs, urbanistes, antropòlegs, economistes, geògrafs, tracten la temàtica del turisme a les illes. I això no és gens contradictori ja que és possible aproximar-se a aquesta problemàtica des de totes les perspectives de les ciències socials: ella constitueix un camp privilegiat per al diăleg pluridisciplinari.

En aquest breu repàs bibliogràfic cal assenyalar l'estudi de Barbaza. ${ }^{17}$ Sobresurt per la seva exhaustivitat i el seu rigor metodologic. La recerca, feta a començament dels anys seixanta, conté moltes indicacions, vàlides encara ara, per a comprendre les transformacions dels sectors econòmics tradicionals, les modificacions del paisatge humà de la Costa Brava i la incidència del turisme. Barceló, Barbaza, ens expliquen l'evolució geogràfica i històtica del fenomen. Més recentment, Farreras ${ }^{18}$ també ha fet aportacions d'interès des d'aquesta darrera perspectiva.

12. Pulido, A., «Introducción a un análisis econométrico del turismo», quadern núm, 5, Instituto Estudios Turisticos, Madrid, 1965.

13. Palomino, A., El milagro turístico (Batcelona: Plaza y Janés, 1972). 1964.

14. Barceló Pons, B., «El turisme a les Illes Balears», Serra d'Or, març-abril

15. No és el cas ací de tractar de fer una revisió a fons de la bibłiografia del turisme.

16. Servei d'Estudis de la Banca Catalana, «La via menorquina»i «L'economia de Mallorca», Barcelona 1978. 1966).

17. Barbaza, Y., Le paysage bumain de la Costa Brava (París: A. Colin, 1973).

18. Farreras, A., El turisme a Catalunya del 1931 al 1936 (Barcelona: Porter, 
Pràcticament tothom està d'acord a considerar el turisme com un dels motors del desenvolupament econòmic de l'Estat espanyol. Evidentment un dels problemes per a la ciència econòmica és el d'afinar les seves eines metodològiques a l'hora d'estudiar el turisme i no quedar-se al nivell de les estadístiques concernents a entrades i sortides i despeses dels turistes. Sabartés i Cals ${ }^{19}$ ho intenten amb diferents resultats si bé constitueixen dues referències obligades en la dimensió econòmica. Unna i altra no es limiten a parlar d'oferta $i$ demanda $i$, tot partint d'un marc més general, fan intervenir altres elements. Com per exemple, els costos socials i les conseqüències territorials $\mathrm{i}$ urbanístiques. En aquests dos terrenys cal citar també, la recerca de Campistol i Lluch ${ }^{20}$ sobre els efectes polaritzadors del turisme de Sant Feliu a Palamós, i els informes que últimament comencen a fer els Collegis d'Arquitectes. Gaviria l'any $1971^{21}$ ja assenyalava les relacions entre camp i ciutat en I'interior d'una teoria de l'oci. I, Bohigas, ${ }^{22}$ en un agut article ensenya la complementarietat entre la casa de Ia ciutat $\mathrm{i}$ la torre d'estiueig per a una certa burgesia. Pel que fa al caos urbanístic, ultra la recomanable contemplació in situ, val la pena tenir en compte el número zero de la tevista $\mathrm{CAU}$. $^{23}$

Quant al tipus de turisme que ve al país, el Ministeri corresponent n'ha fet alguns treballs, així com entitats privades entre les que cal citar al Centre d'Estudis Tècnics Turístics i les que giren al voltant de la revista Editur. Ata bé, la majoria d'aquestes observacions no superen la mecànica de l'enquesta directa i se situen en l'òptica de l'aprofitament dels turistes. En canvi, l'anàlisi de Gibert ${ }^{24}$ intenta comprendre els mecanismes que actuen damunt les motivacions i els canals turístics. Martínez ${ }^{25}$ ha treballat sobre com es ven l'objecte turístic i Gaviria, ${ }^{26}$ a partir d'una recerca refe.

19. Sabartés, B., «Teoría económica del turismo y su aplicación al caso espa. frol», Horizonte Español (Patís: Ruedo Ibérico, 1966), vol. 2. Cals, J., Turismo y politica taristica en España: una aproximación (Barcelona: Ariel, 1974).

20. Campistol, P. i Lluch, E., «Les conseqüències comatcals del turisme a la Costa Brava» (Barcelona: Servei d'Estudis Banca Catalana, 1972).

21. Gaviria, M., Campo, urbe y espacio del ocio (Madrid: Siglo XXI, 1971).

22. Bohigas, $O$, La arquitectura del veraneo: entre la sinceridad y la bipocresia. Contra una arquitectura adjetivada (Barcelona: Edicions 62, 1966).

23. CAU, núm. 0, "Turismo", Revista del Collegi d'Aparelladors i Arquitectes tècrics de Catalunya $i$ Balears, marc 1970.

24. Gibert, A., «El crack turístico de la Costa Brava» (Girona: Cambra de Comerç, 1972).

25. Martínez, A., «L'image touristique de la Costa Brava», Universitat de Montpeller, 1977.

26. Gaviria, M., España a gogo. Turismo charter y neocolonialismo del espacio (Madtid: Turner, 1974). 
rida a la Costa del Sol, també ha estudiat l'impacte de la propaganda. Petò la recerca de Gaviria es destaca més marcadament perquè explica amb detall un dels processos més significatius del fenomen turístic de massa en els darrers temps, és a dir, l'augment del poder de les grans agències internacionals en el negoci turístic a través dels tours operators.

Un altre aspecte d'importància creixent però que fins ara no ha rebut tractament és el de la gravitació del turisme en la trajectòria del municipi. Cal o no cal parlar de municipis turístics? Quines especificitats tenen $\mathrm{i}$ com aquestes condicionen econòmicament, socialment i culturalment l'evolució dels ajuntaments? Per ara només està damunt la taula, l'article de Romagueta, que tracta de les hisendes dels municipis de la Costa Brava ${ }^{27}$ i l'evidència dels problemes generats per les diferències dels volums de població i la continuïtat dels equipaments collectius. Aquest és un debat obert $i$ en la mesura en què altres sectors $i$ forces diferents de les actuals s'incorporin als ajuntaments, prendzà una virulència i una acuïtat especials. Una planificació democràtica haurà d'optar, sense caure necessàriament en l'exclusivitat, entre el caos o el sanejament urbanístic, entre el turisme residencial o el dels grans hotels, entre el turisme internacional o l'intern, entre la venda d'una o altra imatge. Qüestions que no solament afecten als futurs batlles sino també a tota instància de poder polític $i$ administratiu.

En qualsevol circumstància, hom haurà de tenir en compte quina ha estat la vida anterior dels pobles de la costa $\mathrm{i}$ com han arribat a la situació actual. I, a manca de recerques econòmiques i sociològiques sabum des, bones són les consideracions dels lletraferits. Potser, fins i tot, són imprescindibles i insubstituibles en la percepció de la realitat social. Cal escoltar les paraules que dicta l'experiència viscuda en aquest necessari colloqui entre el rigor científic i la sensibilitat literària per tal d'enriquir la reflexió collectiva del món que ens envoita.

El diàleg ja està provocat $i$ encetat amb les següents frases de Gaziel: «Els economistes $\mathrm{i}$ altres estudiosos d'aquesta mena de transformacions socials, [...] en deuen saber moltes coses i segurament ens n'explicarien un bull. Petò ells mateixos, si no han contemplat el fenomen amb els propis ulls, és impossible que en tinguin una noció comparable a la simple experiència dels qui els visquérem. No: per haver-ne un concepte, la ciència d'ells basta; però per a conèixer-ho a fons cal tenir-ne un record, com

27. Romagueta, R., «La hisenda municipal catalana: el cas de la Costa Brava». Publicació d'Intormación Economica, Banca Catalana, núm. 44. 
una llavor viva, conservada en el test més recòndit i misteriós, que és la memòria individual.» ${ }^{28}$

No es tracta de privilegiar les formes de coneixement subjectiu, sinó d'assenyalar l'interès d'un conjunt de publicacions fetes per literats, erudits locals $\mathrm{i}$ cronistes, que reconstitueixen la memòria collectiva. ${ }^{29}$ Així per exemple, res no substitueix per ara el llibre de Gaziel per a entendre el Sant Felits vuitcentista suraire i pescador. Les obres completes de Josep Pla són lectura obligada per a qui vol endinsar-se en el món de la Costa. Alguns dels seus «homenots», els volums dedicats al mar, la guia de la Costa Brava i el seu Cadaqués, no poden deixar-se de costat. En aquest ordre, Torrent ha fet un bon recull de textos ${ }^{30}$ d'escriptors catalans. Les imatges d'un Ruyra sobre Blanes, les explicacions d'en Palau sobre Tossa, ${ }^{31}$ els comentaris de Costa $\mathrm{Pau}^{32}$ sobre les relacions entre els pescadors $\mathrm{i}$ els turistes són elements gens negligibles. Fins i tot són molt aprofitables les guies turístiques $i$ les impressions gràfiques. ${ }^{33}$

És evident que l'aproftament d'aquests materials ha de tenir en compte els diferents rivells i objectius amb els quals han estat produits. Mes moltes vegades, hom pot trobar-hi pinzellades significatives, idees simptomàtiques, impressions escaients que, desenvolupades, permeten avançar en la diagnosi del cos social. En aquesta perspectiva $i$ per Lloret de Mar, les intuicions contingudes (la petita història viva) en els dos libres d'Esteve Fäbregas i Barri, ${ }^{34}$ han estat de molt valor en el moment de formular el conjunt d'hipòtesis d'aquesta recerca.

Però, i els sociòlegs $\mathrm{i}$ els antropòlegs? Generalment, no han considetat el turisme com un centre d'atenció amb prou interès. Així, quan llur reflexió a propòsit de les telacions socials s'ha centrat en un poble, han escollit les societats rutals interiors. A títol d'exemple, les recerques ja

28. Gaziel, Sant Feliu de la Costa Brava (Barcelona: Aedos, 1963), p. 167.

29. Tampoc no es tracta de relacionar totes les publicacions locals, sinó simplement de citar-ne algunes de significatives i útils

30. Torrent, J., La Costa Brava vista pels escriptors catalans (Batcelona: Batcino, 1958).

31. Palau, I, Llibre de Tossa (Barcelona: Selecta, 1952).

32. Costa Pau, M., Turistes, sirenes $i$ gent del pais (Barcelona: Ariel, 1966).

33. Vegeu, per exemple, Cesc, La Costa Brava (Barcelona: Lumen, 1963). Mas, F., Paisaje y color en Lloret de Mar (Barcelona: Eds. Unidas, 1967) i Misetachs, X., Costa Brava sbow (Barcelona: Kayros, 1966).

34. Fàbregas i Barri, E, Lloret de Mar (Barcelona: Selecta, 1959) i Vint anys de turisme a la Costa Brava (Barcelona: Selecta, 1970). Vull agrair tant a Fàbregas com a l'alcalde de Lloret i a altres persones del poble que no és el cas mencionar ací, les facilitats donades per a portat a terme les primeres fases del treball. 
clàssiques de Pitt Rivers i Brenau, ${ }^{35}$ tot passant per les de Lison Tolosane i Pérez Díaz, ${ }^{36}$ per acabar en les més recents de Mira, ${ }^{37}$ posen de telleu les transformacions de determinats pobles andalusos, gallecs, castellans i del País Valencià, si bé les viles costaneres no els han atret per ara. Amando de Miguel també nota en la introducció al 1 libre de Cals, ${ }^{38}$ aquesta paradoxal falta d'investigacions socials.

Paradoxal perquè, tal com determina Hamsen, ${ }^{39}$ els turistes no solament aporten divises, sinó que ofereixen, creen uns nous modes de consum i estimulen la demanda en un sentit molt precís. Però curiosament, desptés d'aquestes afirmacions, l'esmentat autor $\mathrm{ni}$ tan sols intenta profunditzar quant a les conseqüències d'aquests processos en les pràctiques socials de Vilafranca. De fet, E. Mira i Gil Muñoz, ${ }^{40}$ en les seves respectives publicacions sobre l'evolució d'Eivissa i Formentera, insinuen la possibilitat que es produeixin diferenciacions en l'aprofitament econòmic del turisme, la qual cosa propaga tensions entre els diferents grups socials i àdhuc afecta a la suposada unitat social illenca anterior a l'arribada dels turistes. Piñeroba, ${ }^{41}$ en la seva tesi sobre Formentera, insisteix en el mateix sentit.

Tanmateix l'augment dels nivells de renda dels pobles afectats per la riuada turística és vist amb satisfacció per la majoria dels habitants d'aquests, encara que, com significa Greenwood, ${ }^{42}$ pels bascos de Fuenterrabia la indústria turística, pel seu caràcter aleatori i estacional provoca una inestabilitat i unes actituds d'ansietat i frustració genetals. El mateix autor, en un altre article, indica la influència del turisme en les construc* cions i l'urbanisme, i com la política municipal queda condicionada per aquest fenomen. També ho constata Boix Selva, ${ }^{43}$ per a la Costa Brava.

35. Pitt Rivers, J. A., Los bombres de la sierra (Barcelona: Grijalbo, 1971). Brenau, T., Soutb from Granada (Londres: Penguin Books, 1963).

36. Lison Tolosane, Belmonte de los Caballeros (Oxford: University Press, 1966). Pérez Díaz, U., Estructura social del campo y éxodo rural (Madrid: Ed. Tecnos, 1966).

37. Mira, J. F., Un estudi d'antropologia soctal al Pais Valencid (Barcelona: Edicions 62, 1973).

38. Cals, J., op. cit.

39. Hamsen, E. C., Rural Catalonid under the Franco regime (Carabridge: University Press, 1977), pp. 7.8 i 89.

40. Mira, E., Estudi sociologgic d'Eivissa (Barcelona: Fundació Bofill, 1974), p. 208. Gil Muñoz, C., Formentera, una comunidad en evolución (Barcelona: Dopesa, 1971).

41. Pineroba, J., «Tourism: its penetration and development on a Spanish Island», N. Y. New school for Social Research, 1975.

42. Greenwood, D., «Culture by the Pound; an anthropological perspective on tourism as a cultural commodization». Paper delivered at the 1974 Annual Meetings of the American Anthropological Association. Mèxic, 1974.

43. Boix Selva, E. M., «Influencia del turismo y del urbanismo en los procesos 
Utilitzant l'enquesta com a mètode, Duocastella ha procurat esbrinar algunes relacions entre eis turistes i la població autòctona a la Costa Brava, al Maresme i a Salou. ${ }^{44}$ Ara bé, i malgrat l'amplada de les mostres, la preocupació primordial que gira al voltant de la pràctica religiosa, limita l'abast del treball i el colloca més aviat en la perspectiva de la «sociologia pastoral». En una línia semblant, cald̛ria citar el númeto monogràfic dedicat a turisme i pastoral, de la revista Qüestions de vida cristiana l'any $1971 .^{45}$ Mereixen una ressenya la temptativa de Nualart $i$, especialment, de Vicente, en parlar de l'impacte social del turisme, «l'autocrítica» de Pifarré del turistne de santuari, l'explicació d'unes experiències viscudes treballant com a cambreres. L'observació participant es manifesta, ací, més enriquidora que l'enquesta.

La utilització d'aquesta metodologia permet a $\mathrm{O}$. Pi Sunyer ${ }^{46}$ plantejar agudament algunes premisses significatives: el turisme com a forma d'industrialització i modernització, l'agudització de les tensions i el reforçament de les divisions de classe, la contradicció del turista explotador-explotat, el paper dels estiuejants i l'increment dels mecanismes de dependència.

Realment, és el camí començat a traçar per Pi Sunyer, el que assenyala la trajectòtia que cal recórrer, si hom vol endinsar-se en la complexa problemàtica del turisme. La irreversibilitat d'alguns dels canvis que provoca marca la urgència de no retardar-ne més l'estudi. La seva creixent importància per al nostre país és un repte que els científics socials, sensibles pel seu futur, no poden ja oblidar.

\section{Lloret, cruilla de dues civilitzacions}

Per a intentar comprendre alguns processos bàsics del turisme $i$ eixam. plar i profunditzar les hipòtesis teòriques, calia baixar a una societat concreta $\mathrm{i}$ escollir un $11 \mathrm{c}^{47}$ amb unes determinades característiques significatives.

de transculturación». Asamblea Provincial de Turismo, Diputación Provincial de Barcelona. Barcelona, 1974.

44. Duocastella, R. «Sociología del turismo en la Costa Brava». Fondo de ISEC de Cajas de Ahorro, 1966. «El turisme a Salou», ISPA, 1967, i «Sociología y pastoral del turismo en la Costa Brava y Maresme», Fondo ISEC, 1969.

45. Qüestions de vida cristiana, «Turisme i pastoral», núm. 56. Montserrat, 1971.

46. Pi Sunyer, O., «Tourism and its discontents: the impact of a New Industry on a Catalan Community». Studies in European Society, núm. 1, juliol 1973.

47. Un dels límits de l'estudi és la manca d'altres anàtisis de situacions sem- 
Elegit Lloret no és fruit de l'atzar, ja que aquest poble és de fet una cruilla en la qual es troben dues civilitzacions, la del Nord que baixa a la recerca del sol per gaudir d'unes vacances i la del Sud que puja a trobar feina. En aquest sentit, és un exemple d'un enfrontament molt més ampli que el del turisme: el de l'Europa més avançada amb l'Europa rural. Enmig d'aquesta pugna, una societat mediterrània, tradicionalment oberta al mar, assentada sobre una economia primària, amb una cultura $i$ una Ilengua pròpies i diferenciades, situada en el país més industrialitzat d'un Estat, dependent i perifèric.

A més, Lloret passa d'uns 9.000 habitants durant l'hivern a gairebé 120.000 persones a l'estiu; és un dels sis primers de tot l'Estat, en nombre d'hotels en xifres absolutes $i$ segurament el primer en relatives, $i$ ha doblat la seva població en els darrers vint anys. És difícil trobar un exemple més espectacular i representatiu. En qualsevol cas, és comparable amb d'altres com Benidorm, Tortemolinos, Sitges, Salou, El Arenal, Calella...

La pregunta clau que defineix l'objectiu principal d'aquesta recerca es podria formular així: fins a quin punt i com el turisme ha transformat les estructures socials del poble de Llotet de Mar? Hom podria proposar quatre grans possibilitats:

Una primera hipòtesi consistiria a suposar que les modificacions econòmiques $i$ demogràfiques sumades amb les pressions de les cultures diverses, treballadors del Sud, barcelonins i turistes estrangers, transformen totalment el conjunt d'estructures econòmiques, socials $\mathrm{i}$ ideològiques del poble, destruint-lo com a tal.

Una segona, tot $\mathrm{i}$ acceptant la destrucció de les estructures fonamentals, veuria la permanència d'elements marginals de la comunitat origina?.

Una tercera hipòtesi consideraria la destrucció dels elements accidentals, però conservant-ne els substancials.

Per fi, una quarta, és la de la continuitat, introduint les modifica. cions pròpies de la societat catalana i espanyola, però com si el turistne rellisqués per damunt del teixit social.

blants que permetrien un enriquiment comparatiu. Es d'esperat que aquest assaig esperoni alttes treballs sense els quals la recerca sobre Lloret resta incompleta. Per raons de veïnatge la comparació amb Tossa, vila turística, s'imposa, així com també Ia de Blanes, vila industrial-pesquero-turística, encaza que un aitre sentit. ¿' $S^{\prime}$ han donat els mateixos processos a Calelta i Sitges, posem per cas? ¿Els habitants de Benidorm han reaccionat de forma semblant als de Lloret?, $i$ els de Torremolinos? L'especificitat valenciana $\mathrm{i}$ andalusa, com ha jugat? La comparació amb un lloc com l'Arenal a Mallorca, on no hi havia pràcticament ningú, també podria ésser enriquidora. La confrontació amb els resultats de Roses i Fuanterrabia ha fet avançar força l'esquema teòric. 
Endinsar-se empíricament en aquestes conjectures planteja una gran quantitat de problemes. Uns de fonamentals són els d'ordre metodològic, ${ }^{48}$ els quals comprenen des de la publicitat de la recerca i el paper de l'investigador fins al lligam de les tècniques sociològiques $\mathrm{i}$ antropològiques, tot passant per la necessitat d'articular una sèrie d'àrees tan diverses com els llinatges familiars, les festes populars, els canals de comercialització, el paper dels vells, les relacions sexuals, la infraestructura productiva, l'especulació de la terra, les forces i les idees polítiques, els grups i les institucions socials, els valors dominants i els dominats.

L'avantatge d'escoliir com a unitat d'anàlisi un poble determinat consisteix en què la pretensió de globalitat esdevé possible. Tots els racons de la vida social haurien d'ésser examinats. Això exigeix un gran equip i molts mitjans o una permanència de llarga durada. ${ }^{49}$ La primera solució pot tenir les virtualitats del treball collectiu. La segona, pot ésser més sensible al pas del temps. Fet especialment estratègic si, com és el cas, l'objectiu és estudiar un cos social com a conjunt.

L'altre eix que travessa la recerca és la intersecció entre les classes socials i el fet nacional. Dues dimensions que estructuren i omplen de contingut l'esfera de la instància collectiva.

Però per a desembocar en aquest aspecte de la realitat cal un pas previ d'acumulació d'informació. En aital sentit i ultra un balanç bibliogràffe, la primeta fase ha consistit a reunit un màxim de referències quantitatives i qualitatives del poble de Lloret de Mar. Des dels censos, padrons, licències fiscals i permisos de construcció, tot passant per la informació escrita sobre Lloret, continuant per l'autoinformació produĩda i acabant en la tradició i l'expressió orals, hom ha intentat aplegar una base objectiva. ${ }^{50}$ A partir de la qual, en una tercera fase poden començar-se a contrastar les hipòtesis teobriques i a formular un cert nombre d'esquemes de treball. $\mathrm{La}$ verificació d'aquests inclou el qüestionari només com a darrera mesura. Més aviat es tracta de tecórter a aitres tècniques menys fotmalment passives $\mathrm{i}$ que s'integren millor amb el mètode de l'observació participant.

48. No és el cas d'explicat en aquest breu article la complexitat metodològica d'una recerca que pretén abastar el conjunt de la vida social d'un poble.

49. Pràcticament, no hi ha any en què l'autor no deixi de participar en la quotidianeitat de Lloret. Des de fa uns sis anys que aquesta participació s'ha tornat introspectiva del cos social i reflexiva amb respecte a la seva evolució.

50. De passada, un «subproducte» gens menyspreable de la recerca, ha estat formular un model del gènere d'informació que es pos treure d'un Ajuntament com el de Lloret. 
Aquestes diferents fases no són estrictament cronològiques. Així s'ha avançat molt en el coneixement de la base estadística referent a la població, a les activitats econòmiques, etc..., $i$ en la comprensió de certs mecanismes interns. En canvi la contemplació d'altres camps ha estat postposada per a altres fases.

En l'estadi actual de la recerca es podia pensar que fins a cert punt es verificava la primera hipòtesi teòrica; això suposava la destrucció de la comunitat lloretenca subjugada per forces exteriors molt superiors a ella. Especialment si s'adoptava la perspectiva que un canvi en l'esquema productiu i del conjunt de l'activitat econòmica havia de suscitar una revolució profunda en les relacions socials. L'extinció de les activitats agrícoles i pesqueres que comportaven una determinada organització social suposadament primitiva, autònoma, homogènia i cohesionada, devien deixar pas amb la dedicació al turisme, a un sistema social complex, heterogeni, dependent i desilorigat, La destrucció de la producció primitiva portava segons aquesta hipòtesi a la desaparició de la comunitat primitiva.

Certament, aquest plantejament establia una estricta correlació entre sistema econòmic $\mathbf{i}$ social, sense tenir en compte les autonomies de les esferes socials $\mathrm{i}$ culturals $\mathrm{i}$ les capacitats de resistència $\mathrm{i}$ adaptació davant de les invasions exteriors.

Doncs, ja en la fase present hom pot qualificar aquest model com d'excessivament mecanicista i simplista. Efectivament, l'anàlisi de la societat Iloretenca ha fet aparèixer molts elements difícilment explicables en Ia lògica antetior. Progressivament s'ha vist més clara la necessitat de donar entrada a noves variables i a un esquema general toés ric.

\section{La destrucció de l'economia tradicional}

Després de la guerra, Lloret de Mar vivia encara sobre la base d'una activitat extractiva. L'any 1945 treballava el 34,2\% del conjunt de la població. El $96,7 \%$ d'aquesta població activa eren homes. EI $60,18 \%$ treballaven en el sector primati, dels quals el $86,9 \%$ en l'agricultura i el $13 \%$ en la pesca. Un $20 \%$ treballava en el sector secundari que es repartia equitativament en la construcció i en l'artesanat. L'altre $20 \%$ de la població activa treballava en el terciari; d'aquest petcentatge només un $3,66 \%$ ho feia en l'hoteleria. El patró de pesca i el propietari agrícola eren eis prototipus del poder econòmic i, junt amb altres figures més litigades al podet social (rector, metge, farmacèutic, jutge...), constituien el nucli dominant del poble. Al costat d'uns pocs grans propietaris hi havia un minifundisme no exagerat, en el qual l'horta ( 90 hectàrees en 1950) ju- 
gava un paper no negligible $i$ on les 700 hectàrees de secà es repartien en conreus dedicats a la vinya $(40 \%)$, cereals $(50 \%)$ i fruites $(10 \%)$. Una certa producció ramadera ajudava a viure en un règim relativament autàrquic (en 1950 s'exportaven 1.200 tones de patates cap a Anglaterra). La navegació a vela, les drassanes i el comerç amb Amèrica, així com la indústria del suro, eren records per la majoria, tot i que les cases dels indians, algunes fortunes lioretenques $i$ aiguns tapers, continuaven fent present un passat poderós. La pesca relativament florent $(83 \mathrm{Fes}$ cadors en 1945, 160 en 1957), puntaites, espardenyers i tallers de gèneres de punt, acabaven de definir l'economia llotetenca de després de la guerra civil.

En els anys setanta el panorama ha canviat totalment. La taxa de població activa ha augmentat fins el $40 \%$; especialment s'ha produit una incorporació de la dona al treball temunerat $(14,64 \%$ població activa femenina). Si bé en 1945 tres de cada cinc lloretencs que treballaven ho feien en el sector primari, en 1970 només ho fa un de cada dotze. L'agricultura de Lloret queda desmantellada en aquests vint-i-cinc anys. La terra cultivable ha passat del $85 \%$ el 1950, al $37 \%$ en 1971 del total. De 1950 a 1960 la disminució no és gaire important i es localitza en les terres menys bones de secà. Cap a 1960 comença el fenomen de les urbaniłzacions (Canyelles, Lloret de Dalt, Mongoda, Coll de Llop), desapareixent progressivament els cereals i la vinya. De 1963 a 1971 el territori agrícola es redueix de 2.200 hectàrees. Només queden en l'actualiłat algunes petites propietats de regadiu intensin; tres propietats mínimament rendables ocupen els únics 13 assalariats, tots ells immigrats andalusos. La resta de propietats són familiars. L'edat mitjana de l'agricultor lloretenc era en 1972 de 57 anys. Cada anyada la població agrícola envelleix sense possibilitats de renovació. La producció s'esmorteeix (el 1972 només es produien vint mil quilograms de patates) i és tota ella venguda als hotels de Lloret. De 1960 a 1969, desapareix gairebé totalment l'explotació del bosc. Si no canvien les circurastàncies, fins $i$ tot els nuclis de regadiu intensiu d'alta productivitat encara existents estan destinats a desaparèixer en mans de les urbanitzacions $\mathrm{i}$ de les construccions. L'hoteler i l'urbanitzador substitueixen el pagès.

El declivi de la pesca s'inicia els anys 1958-1960. Això s'explica perquè, uitra els problemes genèrics de la pesca a la Mediterrània, l'absència d'un port (en 1960, 100 sortides: en 1974 únicament 65 sortides), la dedicació a altres feines lligades al turisme (creuers, viatges marítims), la manca de mitjans financers $\mathrm{i}$ tècnics, fan que sols quedin 53 pescadors 
en 1973, dels quals solament $8 \circ 9$ es guanyen la vida; tots ells més grans de quaranta+cinc anys.

La població activa del secundari passa del $20 \%$ del total en 1940 , al $40 \%$ en 1970: de 210 persones a 1.105. La construcció és la que més ha augmentat, car si en 1940 hi havien 7 mestres d'obres i cap empresa, l'any 1970 compta amb 9 mestres d'obres i 25 empreses dedicades a la construcció. Evidentment, també les empreses relacionades amb aquest sector han progressat parallelament (fusteria, electricitat, pintura), i en $1972 \mathrm{el}$ nombre de contribuents locals era de 152. Que és un index de la incorporació de la mà d'obra lloretenca als llocs qualificats d'aquest sector.

Pràcticament, l'artesanat tradicional ha desaparegut i ha aparegut un nou tipus d'artesanat dependent del turisme. Com és típic d'una economia turística, el sector terciari és el que més ha crescut. Un de cada dos lloretencs que treballen ho fan directament en aquest sector. De 1957 a 1967 s'obren 71 comerços dedicats a vendre productes d'alimentació, en 1974 n'hi havia més del doble (143). De 1957 a 1967 s'installen 56 magatzems de souvenirs, 27 de vestits i confecció, 12 de bisuteria, etc. En 1972 es totalitzaven 392 botigues. Lloret s'ha transformat en un gran «basar»...

Totes les agències internacionals importants són presents a Lloret de Mar des de 1960; actualment n'hi ha 22. Agències de lloguer i immobiliàries han crescut com els bolets. En 1974 es comptaven 6 sucursals de bancs, més la de la Caixa.

Ara bé, cap altra activitat ha conegut un boom tan extraordinari com l'hoteleria. En 1950 existien a Lloret 8 hotels i 206 llits. EI 1974 n'hi ha 234 i 24.945 llits, segons xifres oficials. Cal afegir-hi més de 10.000 liits en els apartaments que han augmentat molt darrerament, 4 càmpings amb més de 4.500 llocs, les urbanitzacions, etc. Per acabar la mostra, s'hi hauria d'afegir 312 bars (comptant els dels hotels) i més de 30 night clubs.

Realment, l'economia de Lloret s'ha alterat radicalment en aquest últim quart de segle. Tot el sistema productiu ha variat de sentit $i$ de ritme. La relativa autarquia s'ha convertit en total dependència de l'exterior en homes, capitals i tecnologia. Els mecanismes d'acumulació s'han transformat $i$ augmentat. Els poders econòmics tradicionals han estat difuits $\mathrm{i}$ ara, immobiliàries, constructors, hotelets, agències de viatge, controladors dels circuits comercials o fnancers formen les noves oligarquies. Els centres importants de decisió econòmica s'han allunyat de l'òtbita lloretenca. 
La immigració, factor clau de l'expansió demogràfica

Amb lleugeres variacions, Lloret de Mar havia oscillat des de 1876 fins a 1960 entre 3.000 i 4.000 habitants. A partir d'aquesta dartera dècada, el ritme de creixement poblacional augmenta tant, que en quinze anys la població es duplica. Cal distingir dues fases:

a) La primera de 1945 a 1960 . El creixement vegetatiu (110 persones) és pràcticament igual al saldo migratori (99 persones). La població creix lentament. La natalitat és baixa $(7,5 \%$ de 1955 a 1959), així com la mortalitat $(7,8 \%$ pel tnateix període). La taxa de creixement de la població és del $3 \%$. El $52 \%$ dels immigrats a Lloret entre 1951 i 1962 són catalans i $\tan$ sols el $8 \%$ són andalusos. El turisme de massa tot just comença.

b) Cap al 1964 s'afirma el procés iniciat a finals dels cinquanta i la corba de la població total de Lloret es dispara. La natalitat augmenta (13\% de 1965 a 1969) més que la mortalitat (10,4\%), però és sobretot el saldo migratori el factor clau de l'expansió demogràfica. De 1962 a 1969, arriben 1.589 immigrats comptabilitzats, dels quals sols el $30 \%$ són d'origen català i el $53 \%$ vénen d'Andalusia. Dels primets, el $30 \%$ són quadres $i$ to assalariats; dels segons el percentatge d'assalariats puja al $95 \%$. Els primers són comerciants, hotelers, administradors $\mathrm{i}$ artesans lligats a la construcció. Els segons són fonamentaiment mà d'obra no qualificada per a I'hoteleria i la construcció.

En els darrers anys s'accentua la immigració estable d'estrangers (especialment alemanys, anglesos i holandesos), la majoria d'ells vinguts a gestionar les inversions d'aquests països i en algun cas a installar algun comerç familiar (botiga, bar).

Així, doncs, Lloret s'ha vist sotmès a un canvi profund en la seva població fins al punt que més de la meitat de la població estable no hi ha nascut. La piràmide d'edats era regressiva en 1945 i és força progressiva en 1970. El percentatge de població de més de 55 anys era de $22,4 \%$ en 1940 ; en 1970 baixava al $16,3 \%$. La forta natalitat de la gent del Sud s'ha imposat a nivell de la població total. De 1962 a 1973, Lloret creixia el $110 \%$.

\section{Pressions socials $i$ classes socials}

Els estiuejants de Barcelona, de Girona i també d'altres poblacions catalanes, són els primers a modificar sense gaire estridencia el pai- 
satge urbanístic de Lloret, bé aprofitant veiles cases de pescadors, bé edificant torres d'estiueig al llarg del passeig del mar i en els llocs més privilegiats ( $S_{a}$ Cáleta, etc.). Alguns d'aquests estiuejants són llozetencs que retornen els estius al poble i ocupen llurs cases pairals.

Les relacions amb la gent del poble van de l'extrem en el qual la dominació de classe i econòmica s'expressa i genera la servitud i l'oposició dels autòctons (exemples: l'antagonisme dels joves i l'adjectiu de «merdejants») a l'altre extrem, en què hi ha collaboració en certes activitats (anar a cercar bolets, a pescar), esportives (futbol, «els Pops de Lloret de Mar») i festivitats (el ball de plaça). Però, en general, ni «els del poble» no apreciaven massa «els de la colònia», ni aquests feien gaires coses per a aproximar-se als primers.

Tanmateix amb el descobriment de la gallina dels ous d'or del tutisme, el paper de la burgesia urbana ha pres molta més importància, ja que han estat molts d'ells que, en una segona fase, s'han aprofitat més del turisme fent urbanitzacions, obrint cadenes d'hotels, grans magat* zems, etc. L'articulació amb les capes riques del poble s'ha produit amb els que pertanyien als sectors catalans de la mitjana burgesia barcelonina (casaments, «el casinet», etc.). En canvi, els sectors més oligàrquics, molts de cultura castellana, han mantingut les distàncies i han construit un mon a part (Club Nautic, xalets a la Roca Grossa). Les relacions de dependència del poble envers la burgesia barcelonina i gironina s'han traduit en molts casos en relacions bé de competència, bé d'associació.

Una pressió molt més aclaparadora i bàsica ha estat la dels immigrants del Sud. Com en la majoria de viles i ciutats catalanes, una riuada de gent forana ha arribat i s'ha installat a Lloret de Mar. Expulsats per la manca de treball de llur regió d'origen, vénen a la Costa Brava, molt sovint a «fer la temporada», però moits acaben quedant-s'hi $i$ adés cridant la resta de la família. Liur cultura i liur pràctica social xoca amb la dels autòctons.

La importància relativa d'aquest nou proletariat, la mena de treball, la localització del seu habitacle, l'escola, l'estructura social de la comunitat receptora $i$ les actituds ideològiques, condicionen la seva integració o no integració en la nova societat. En el cas de Lloret el xoc ha estat considexable donats: $a$ ) el volum demogràfic dels immigrants; $b$ ) la constitució de barris nous $i$ apartats del centre urbà; $c$ ) una escola espanyola, hostil primer i reticent després a donar entrada a elements culturals $i$ linguístics catalans; d) un tipus de treball estacional com constmucció, hoteleria, co. merç i que no facilita la promoció professional, i $e$ ) un teixit social relativament descohesionat amb pocs mecanismes i forces integradors. 
Els cent vint mil turistes que cada estiu inunden els carrers i les platges de Lloret formen un exèrcit heterogeni $i$ divers. Entre el parlar $i$ el fer d'un islandès $i$ un italià, un suec $i$ un grec hi ha poques similituds. Pero, en general, la majoria dels turistes formen part de la classe treballadora i de la petita burgesia de llurs paissos respectius. Això homogeneitza llurs posicions i comportaments. La gran majoria provenen d'una Eutopa industrialitzada i tecrificada, amb nivells superiors de consum i una cultura standaritzada i alienant. Generalment tenen una imatge tòpica i mítica del Spain is different i molt pocs volen travessar el món fet a Ilut mida que se'ls ofereix i se'ls ven. Vénen de vacances de vegades guanyades a pols, volen oblidar llur vida quotidiana $i$, sobretot, ultra el sol, el vi, i el latin lover, desitgen evadir-se i que el país que visiten s'assembli a la idea que els han venut. Però també volen retrobar uns certs elements constitutius de llur identitat i llur pràctica corrents.

Això genera dues pressions diferents sobre el poble. Aquest respon tractant d'apropar-se al màxim al model definit. I, ací, cal assenyalar la responsabilitat de Ia presentació unitària, mixtificadora, folkloritzada de la cultura de tots els pobles de la península, que l'Estat ha portat a terme $i$ que les autoritats públiques tampoc han desdit. La gent ha hagut de disfressar-se (cantaores de flamenco amb accent de Vidreres, més d'una lagarterana que salava), i d'inventar-se els més estranys acudits per a guanyar-se la vida tot $i$ venent els productes $i$ les situacions més estrambòtics $i$ artificials.

L'altra demanda que els ha calgut satisfer és la contínua pretensió del turista de tetrobat el seu propi ambient. Del five o'clock tea angiès, als sucrosos pastissos alemanys, tot passant pel steak frites francès, els soferts lloretencs s'han imaginat una nova gastronomia. Els pubs estil londonià, les cafeteries vieneses, les sales de festes tiroleses, han creat un nou tipus de consum al qual hom ha tractat d'adaptar-se. Adaptació no sense consequiències tant en l'economia de Lloret com en la vida social, ja que els turistes també porten idees, cultura i comportaments no solament diferents, sinó a vegades contraris, que posen en qüestió l'ordre moral dominant.

Molt esquemàticament, l'estructura social de Lloret s'ha transformat a través dels processos següents: en primer lloc, s'ha constituït una nova burgesia integrada per certs sectors del poble $\mathrm{i}$ per «senyors» de Batcelona i Girona, que desplacen l'antic grup dominant i que controlen eis sectors claus de les noves formes d'acumulació (urbanitzacions, grans hotels, monopolis comercials). En una fase posterior, el poder econònic i financer se situa fora de Lloret amb la intervenció de la banca, de les societats inversores estrangeres $i$ de les grans agències internacionals (tours operators, etc.). 
En segon Iloc, marginació total de la pagesia i dels pescadors, i dels sectors de la petita burgesia local liigats amb oficis o especialitats que desapareixen (puntaires, tapers, boters). Ara bé, altres sectors d'aquesta petita burgesia s'adapten i passen a ésser un element de la nova dinàmica (el forner que es fa hoteler, el patró de pesca que organitza uns viatges turístics pel mar, el petit comerciant de queviures que obre una boutique de souvenirs). En tercer lloc, s'ha format un nou proletariat, vingut de fora $i$ que no té gaire a veure amb la classe treballadota autòctona, la qual, en general, o bé ha deixat d'ésser assalariada (el paleta que ara fa de constructor), o bé ha pujat un esglaó en l'escala professional (el cambrer que fa de maître).

Els immigrants, estacionals en un primer temps, han maidat per quedar-se i obrir-se pas en unes condicions de treball i de vida molt difícils. Per a altres, Lioret simplement ha estat un episodi de lilut vida itinerant.

\section{L'erosió de la societat lloretenca}

Les modificacions profundes econòmico-demogràfiques i els canvis en les classes no podien deixar d'erosionar bona part dels mecanismes i institucions socials.

De la cooperació a l'individualisme: Abans del turisme, l'activitat extractiva base de la vida econòmica del poble, implicava un treball físic, uns certs coneixements d'aprenentatge pràctic i una relació de domini i de dependència amb la natura. El valor central d'aquest sistema era el treball expressat en el desgast d'energia física. Els altres valors eren l'experiència i l'ofici que s'acostumaven a transmetre familiarment. Els fills de pescadors continuaven pescant $i$, els dels pagesos, si la terra donava, solien seguir treballant-la. El diner tenia una importància relativa (l'intercanvi de pro ductes era usual) i les formes de cooperació eren abundants. Així ho imposava l'activitat agrícola (collites, veremes, etc.) i la pesquera (equip de la trenyina, cosir les xarxes, etc.).

Ara, amb la terciarització de l'economia, el treball físic no comporta gairebé aprenentatge (peó de la construcció, cambrer d'hotel) i l'activitat principal és la d'intercanvi. La família perd la funció de transmissió de la professió, i el diner esdevé el valor de referencia. Un dels tòpics lloretencs actuals més freqüent és que ara «tothom va a la seva». Les limitacions que una economia relativament autàrquica imposava a la recerca del màxim hucre personal, han saltat. El metcantilisme desenfrenat suposa 
l'exaltació de l'individualisme. Algunes temptatives d'associació econòmica (cooperativa d'hotels, agrupació per compres) han fracassat. I si això passa a nivell intern, els nous vinguts encara accentuen més aquesta lluita aferrissada pel guany privat, ja siguin els treballadors (guanyar el màxim de sâlari en el curt temps de la temporada), els comerciants (vendre el màxim per amortitzat en tres mesos totes les despeses), els hoteles (aprofitar al màxim els marges que els deixen els lleonins tours operators), ja siguin els constructors (pugnar en la cursa contra la inflació) i els urbanitzadors (especular sobre les diferències de preus).

Una bivernació: Anar a bosc era una activitat freqüent dels lloretencs que coneixien les serralades que els envolten. Les caceres autoritzades o no, el cetcar bolets, el fer llenya, la tertúlia al bar d'en Situ en el passeig, el tentar la roba a la Sènia, etc., formaven part de llur vida normal. Qui mnés qui menys tenia el seu hortet dins o fora de la vila. També qui més qui menys sortia a pescar. El contacte amb la naturalesa era estret, així com la dependència respecte a ella. Tothom sabia que per Santa Rosa i Sant Miquel els temporals impedien mollar i que el de les faves canviava la platja. Perquè sortissin ous de reig calia que plogués després de la festa de les Alegties. Els cicles naturals eren puntejats per celebracions i marcaven els ritmes econòmics i socials al llarg de l'any.

Avui, les pulsacions del cos lloretenc tenen poc a veure amb l'evolució del camp i del mar. Pràcticament els tres mesos d'estiu (que tendeixen a estirar-se cap a cinc) condicionen tota la resta de l'any. Hom viu segons el que guanya durant la temporada; hom la prepara, la planeja, s'organitza i s'estructura al seu voltant. Ja se sap!, els mesos d'octubre, novembre i desembre hom descansa, viatja, fa vacances i concep els fills. Durant els mesos de canícula, la majoria de la gent no pensa en alıta cosa que a exprémer la llimona turística, posant-hi el coll, el braç i el cap si cal. Els períodes de descans i de lleute individual s'esborren emportats per la histèria del treball turístic. La vida collectiva entra en una mena d'bivernació, de la qual no despertarà fins a la tardor.

Fragilitat $i$ dependència de l'exterior: 'Tret dels béns d'equipament i de consum no produïts a Lloret, dels serveis collectius necessaris i dels excedents agrícoles i pesquers, l'economia de Lloret era telativament autosuficient especialment en els anys quaranta. Quatre estiuejants, els representants de comerç, els compradors de peix, frequientaven la vila. La gent d'aquesta anaven a Santa Coloma, capital comarcal, a Girona, que un servei d'autobusos enllaçava, i, excepcionalment, a Barcelona. La comunitat 
Iloretenca no era tancada, la costa sempre ha estat terra de pas i de comunicacions, però sí que vivia força sobre si mateixa.

Penò és més significativa la consciència que hom coneixia la terra que trepitjava $i$ els que trobava pel carrer; que es dominava, no sense problemes, la producció necessària per a la subsistència. Molts malvivien i uns pocs vivien bé, però en definitiva tots sobrevivien en la problemàtica postguerra. Això s'ha esmicolat en el present. Lloret viu volcat cap a l'exterior. Fins el punt que gairebé tot li ve de fora; capitals, turistes, productes, treballadors $i$, el que és pitjor, els seus habitants tenen poca incidencia damunt dels fenòmens que afecten la mateixa existència i el tipus de desenvolupament econòmic triat-imposat de Lloret.

L'engranatge en el qual està abocat Lloret no li deixa, i encara menys en un futur-continuació-del-present, quasi cap marge de maniobra. Les grans agències internacionals dirigint el turisme de massa cap el Nord d'Africa o envers els paisos socialistes, una conflagració militar o una crisi política forta, $i$, el que és més evident, una depressió fins i tot conjuntural del centre d'Europa i d'Anglaterra, poden posar en qüestió radicalment les bases del Lloret way of life.

Aquesta fragilitat $\mathrm{i}$ aquesta dependència explicarien molts comportaments $i$ actituds certament illògics si hom els contempla des de la perspectiva de la continuitat i la solidesa (negatives a canviar d'ofici, de vendre terrenys de cultiu, despeses suntuàries).

Moral, funcions tradicionals i ludisme creixent: $\mathrm{El}$ present es viu més intensament i la posició estalviadota de previsió perd terreny. «Aproftem mentre duri la gallina dels ous d'or», es diuen els lloretencs. Un cert tipus d'heretatge relacionat amb la propietat de la terra (l'hereu i la pubilia) deixa de tenir el sentit primitiu. Les propietats ja han estat venudes o són divisibles i quantificables en termes monetaris. La institució familiar trontolla; ja no transmet l'ofici i els fills es neguen a seguir el treball dels pares. El desenvolupament cultural i dels nivells de formació ajuden a eixamplar l'horitzó del jovent que es resigna difícilment a «enterrar-se a Lloret» i a viure l'kesquizofrènia» econòmica del poble. Els que són universitaris poques vegades hi troben treball. Els conflictes generacionals s'aguditzen. Els vells, anclats en el món antetior, s'integren amb dificultats en els processos actuals $i$ perden poder social.

La dona lloretenca s'ha incorporat al treball remunerat, ha augmentat Ia seva formació $\mathrm{i}$ especiałment té la competència de l'"estrangera». Bo $\mathrm{i}$ que de fet els homes prefereixen «una del país», sobretot per casar-s'hi, la noia s'ha enfrentat amb poc bagatge a una situació mòbil i desconeguda. Si els primers bikinis van provocar la irritació de les loretenques, les joves 
d'ara no acostumen a sorprendre's de res. Valors ancestralment reconeguts són discutits o s'esclafen davant de les necessitats $i$ pràctiques quotidianes. Qui pot dedicar-se a la cuina, tenir cura de la casa, educar els fills treballant deu i dotze hores per dia? Qui gosa defensar a ultrança la virginitat en el país de la disbauxa sexual?

En el remolí estiuenc s'enfondren molts valors morals primigenis, no ja de Lloret sinó de la societat rural catalana, de la carpetovetònica i de la mediterrània. El seny i la moderació, la por a l'autoritat, el respecte a la norma, s'esmicolen en el ludisme i el gaudi, les ganes de viure intensament i l'anticonvencionalisme de la joventut europea. Lloret és, en aquest sentit, un lloc avançat en la batalla que enfronta a concepcions molt diverses del món. Es lògic que institucions que han representat el vell ordre moral, com per exemple I'Església, estiguin a la defensiva, o que els antics sistemes de sanció social ja no serveixin, o que determinades formes culturals quedin antiquades.

Sense la defensa a través d'instàncies polítiques tacionalitzadores, amb una cultura pròpia, sotmesa als embats econòmics, demogràfics, socials i ideològics, quantes escletxes han aparegut en els fonaments de l'edifici social de Lioret? ¿Té aquest suficient cohesió interna per a trobar noves forces i reapuntalar-se? Les manifestacions actuals, tsón el símbol d'una nova vida o bé el cant del cigne?

\section{Readapiacions $i$ resistència de la comunitat lloretenca}

Un saber desempallegar-se: Esteve Fàbregas explica en els seus dos libres que Lloret $s^{\prime}$ ha vist sacsejat en la seva història per greus crisis i sempre ha trobat una sortida. Quan ja no es podien construir vaixells i comerciar amb Cuba i Filipinas va sorgir el suto; quan aquest s'eslianguia, els gèneres de punt van substituir-lo. Barbaza, amb altres paraules, també insisteix sobre la capacitat d'adaptació $i$ de supervivència de la gent de la Costa Brava. Encara que mai la concentració en una sola direcció fou tan intensa, alguns lloretencs continuen conservant una certa distància respecte al turisme $i$ vàries tímides iniciatives sorgeixen en el sentit d'intentar reconvertir el tipus de turisme (d'hivern, espanyol, el casino) i d'enfocar certs recursos cap a altres activitats, com són les dues indústries creades tecentment.

En termes generals, el niveli de vida de Lloret ha augmentat considerablement $i$ els lloretencs gaudeixen d'unes rendes inimaginables fa pocs anys. Des d'un primer nivell d'anàlisi es pot sospitar que foren els més rics els qui més s'han enriquit. Mes això no sempre ha estat així. Per 
exemple, de què servia fa vint-i-cinc anys tenir una muntanya de pins a la vora del mar? En aquella època hom cotitzava més un petit terreny de vinya o una horta prop de la sènia. A vegades, la capacitat cultural, el sentit de l'oportunitat o l'uil viu en els negocis han creat fortunes ràpides i quantioses.

Per altre costat, la mateixa brusquedat de l'onada turística, bé que ha terciaritzat l'economia i ha canviat els centres d'acumulació, ha permès la intervenció autòctona en una primesa fase $i$ el control momentani d'aquests nous centres. En els primers temps la reconversió es feia amb una sabata $i$ una espardenya sense aplicar grans capitals (hom utilitzava les golfes o aixecava un pis), però oferint als turistes un producte d'una certa qualitat. La demanda expansiva, la intervenció exterior que en els principis era catalana, provocaren recótrer a formes de finançament no autoproduïdes. Hom construeix hotels. Les agències internacionals entren en escena oferint contractes avantatjosos que asseguren anticipadament la cobertura de la temporada. El percentatge de clients propis disminueix. Els contractes són cada cop més lleonins. Els marges baixen i el producte es degrada. I això lligat amb la descapitalització de l'empresa turística autòctona, la manca de nivell tècnic d'hostalers i empresaris improvisats, provoca una situació difícil. És evident que, com ja està passant, si no es dóna una associació d'esforços $\mathrm{i}$ una planificació molt ben estudiada, la marginació progressiva dels grups locals i nacionals esdevindrà la llei general.

L'actual moment és decisiu en aquest sentit; els darrers problemes reivindicatius i de cracks hotelers així ho palesen prou.

El reforçament de la cobesio interna: La fragilitat i la dependència de l'exterior, així com les pressions dels altres modes de vida, generen malgrat tot un reforçament dels liggams interns. La pertinença a la comunitat es delimita cada vegada més: «aquest, és fill del poble», "és de Lloret de tota la vida», i es diferencia respecte als altres: «fa temps que han vingut, però no han nascut ací», «és del barri de la Càndida» (barriada creada per a la immigració).

El patriotisme local, gairebé ratllant amb el xovinisme, s'ha mantingut $i$ la rivalitat amb els pobles veïn -especialment amb Blanescontinua jugant un paper important en el procés d'autoreconeixement. El famós corb de Lloret (any 1953) és un exemple de la creació de signes d'identitat (a Lloret hom està convençut que són els de Blanes els causants de la seva mort); els partits de futbol entre les dues poblacions i les topades de les bandes de joves poden sumar-s'hi. Tot i que la relació amb Santa Coloma ha disminuit, per certs motius (notari, compres a l'engròs, 
tabac, etc.) els lloretencs encara s'hi desplacen. Especialment són conscients de la pertinença a la comarca de la Selva $\mathrm{i}$, si més no, cada dissabte a la nit ho recorden amb un deix d'orgull davant de batcelonins $i$ altres: «Ells ballen la sardana a la selvatana!»

«Sou de Lloret, que us adora protectora» és la tonada dels goigs de santa Cristina que cada 24 de juliol canten els lioretencs. Suposar que la santa italiana no és de Lloret és ofendre a tot bon lloretenc per més incrèdul que sigui. La verge de Loreto, patrona del poble, les Álegries, Sant Romà, són sants i festes celebrats majoritàriament. La festa major d'estiu i la d'hivern marquen dos punts àgids del calendari lloretenc. Símbols religiosos i festes laiques ptòpies, participen a envigorir l'adhesió interna.

Ultra les referències calturals obligades - la més notòria és el paràgraf de l'òpera Marina que exalta les platges de Lloret-, els signes de reconeixement intern es multipliquen per a fer front a les invasions exteriors. Hom continua acudint al llinatge, «és de la família d'en...», o a la casa, «ca la Joana», "can Fortuny», per situar les persones. La salutació tradicional en entrar en una casa - «Ah Maria»- és menys utilitzada tot $i$ que permet que el nucli dur es reconegui. Però s'ha creat una nova forma d'identificació verbal: «Oi, ell; oi, ella», especialment repetida en els anys seixanta i a l'estiu, quan la pèrdua d'identitat individual era més evident.

Unes onades migratòries diferents: La pressió demogràfica és notable, però en quina direcció es dirigeix? Sembla evident que la circumstància que la majoria de la població estable de Llotet no hagi nascut al poble canvia gran part de les seves coordenades, però aquesta majoria quantitativa ¿és dominant econòmicament, socialment i culturalment? Tal qüestió, que no és específica de Lloret, no té un únic sentit ni en el temps ni en l'espai. L'onada immigratòria forta es produeix a començament dels anys seixanta. Les arribades anteriors (catalans i una mà d'obra qualificada), i posteriors (estrangers) tenen funció, importància $i$ origen diferents. Així com ho és llur atticulació social.

De fet, i en la mida en què la llengua és un exponent significatiu dels possibles conflictes, Lloret és lògicament una torre de Babel, en la qual es manifesten tota mena d'actituds i de pràctiques lingüístiques: alguns vells de Lloret consideren que "patlen estranger» tots aquells que no s'expressen com ells; en certs bars hom no és servit si no parla anglès o alemany; en els barris suburbials sobretot se sent el castellà, així com en els llocs d'esbarjo i de reunió dels fills de l'alta burgesia. En la pellícula de Forn, La piel quemada, rodada a Lloret, es palesaven les dues posicions 
extremes dels enfrontaments político-lingüistics: «xarnego» i no ladre són dos exemples de rebuig que tanmateix no són els més freqüents. Les activitats esportives, l'escola, els matrimonis mixtos, són gresols integratius. L'assistència a classes de català i la seva demanda per part dels immigrants i la participació de la quitxalla lloretenca en la festivitat de Sant Nicolau (1977), organitzada peis residents estrangers, són dos moments d'un procés complex i que cal analitzar molt més si hom vol donar una resposta més profunda.

L'acomodació estacional i social: Si bé la forta estacionalitat del feno. men turístic imposa uns titmes socials diferents dels naturals, la pràctica social s'acomoda amb aquesta nova situació. $O$ sigui, els prometatges es fan d'hivern a hivern amb lapses estiuencs, la festa major petita el 18 de novembre marca la fi de la temporada i pren un relleu especial. Un fet significatiu: els aplaudiments al final de les sardanes, que tant sorprenen els autòctons, ja no se senten, car els estrangers han desaparegut. Només romanen obertes «les botigues de sempre». Lloret es retroba.

El nou tipus d'economia i societat lloretenques ha imposat noves fun. cions i ha tornat més complex el seu funcionament. Però això és més aviat un avantatge en termes de cohesió social. En efecte, aquest procés permet una més gran participació dels membres de la comunitat en les tasques collectives. Quan només hi ha un club de futbol només hi pot haver un president, un entrenador. Si hi ha diversos equips i diferents esports, el nombre de possibles responsables augmenta. Una major complexitat també limita les rivalitats individuals irteconciliables i enterboleix els antagonismes socials.

Velles consoles $i$ catalanisme popular: Per fi, una hipòtesi a desgranar és la que explicaria fins a quin punt unes pressions socials i culturals centriffugues $\tan$ fortes actuen de tevulsiu en el cos social reforçant els seus corrents centrípets. Corrents contradictoris que van des de peticions lloretenques demanant que es respecti l'ordre públic (enquesta Lloret Gaceta), fins a la constitució i dinàmica de més de trenta associacions existents tot passant per formes d'acomodació i de resistència, per acabar en l'enfortiment de l'expressió nacional catałana.

L'any 1971, Lloret era declarada ciutat pubilla de Catalunya i en aquesta celebració la van cobrir de senyeres. Tothom es preguntava de quines velles consoles s'havien tret tantes banderes amagades tant de temps. Lloret, com tantes altres poblacions, enfonsa encara més les seves arrels en la cultura popular catalana per a resistir millor l'embat de les «tramuntanades» dispersores. 
Les diverses competicions esportives, les exposicions pictòtiques, les audicions musicals, les activitats teatrals, arqueològiques, les sessions de cine-club, l'obertura d'una biblioteca, d'un centre social on s'hi fan cursos diversos, la dinàmica cultural de l'Obreria de Santa Cristina i dels Amics de la Sardana, no semblen ésser manifestacions d'un cos que es mor. L'any 1976, per Sant Romà, un nigbt-club es transformava en envelat. A l'any 1977 torna a haver-hi envelat i Lloret ja no necessita aquestes simbiosis estranyes i significatives d'una certa actitud d'adaptació. La creació de l'Associació de Veïns és una altra verificació de la capacitat d'originar grups nous, fins i tot amb funcions crítiques. Aquest conjunt d'iniciatives no han sorgit com un bolet, sinó que són també el producte d'una lluita soterrada i difícil de molts homes de Lloret que no s'han resignat a deixar-se expoliar de llur patrimoni cultural.

La ritual ballada de sardanes els dissabtes a la nit i en cada festa, el cercavila $i$ el ball de plaça, els aplecs, les caramelles, la processó per mar i l'endrapada posterioz sota el pi, per Santa Cristina, formen part d'un teixit de discursos i pràctiques quotidians gue no es deixen estripar fàcilment. Quin és el contingut polític d'aquesta resistència? ¿Es tracta de reminiscències folklòriques tenyides de reaccionarisme? $¿ O$ més aviat tossuderies populars que no volen deixar-se arrencar el que és seu i que constitueix la seva forma de viure? Una aclaridora tesposta simbòlica: la bandera espanyola ha onejat en la casa dels comtes de Roviralta, en el Club Nàutic $i$ en l'Ajuntament; en les barques dels pescadors $i$ en els carrers ho fa la senyera.

L'anticentralisme, que denuncia el tracte discriminatori de l'Estat respecte a la Costa Brava i la Costa del Sol, la recerca de la pròpia història, l'adhesió al cap i casal i la defensa de l'autonomia local, la polarització a l'entorn dels mateixos esdeveniments, idees i figures catalans, són dimensions de la «catalanitat» dels lloretencs. Aquests es diuen catalans no solament perquè ho són, sinó també per afirmar llur específica singularitat $i$ per recolzar-se en un univers més ampli, davant les erosions i transformacions internes $i$ les pressions extcriors. Però sabem, endemés, que estan obligats a trobar formes d'adaptació i d'obertura vers els altres, si no volen que es cristallitzin dos mons a part: el dels lloretencs $i$ el dels forans que hi viuen $i$ treballen de manera permanent.

\section{JORDr ESTIVILL}

Universitat de Perpinyà

Perpinyà, França 